\title{
Molecular Characterization of Nylon 6,6 and Its Dissolved State in Mixture of Calcium Chloride and Methanol
}

\author{
Makiko Hattori, Masatoshi SaIto, Kunihiko OKajima, \\ and Kenji KAMIDE* \\ Fundamental Research Laboratory of Natural \& Synthetic Polymers, Asahi \\ Chemical Industry, 11-7 Hacchonawate, Takatsuki, Osaka 569, Japan \\ * Department of Education, Kumamoto University, 2-40 Kurokamicho, \\ Kumamoto-shi, Kumamoto 860, Japan
}

(Received December 15, 1994)

\begin{abstract}
An attempt was made to evaluate molecular parameters of poly(hexamethyleneadipamide) (nylon 6,6) in mixture of calcium chloride and methanol with various calcium chloride concentrations (weight fraction $W_{\text {ca }}$ against weight of the solvent mixture) using light scattering method. Dissolved state of the polymer was discussed in connection with the chain conformation based on data of viscosity, adiabatic compressibility, infrared (IR) spectra and ${ }^{1} \mathrm{H}$ and ${ }^{13} \mathrm{C}$ NMR spectra. The second virial coefficient $A_{2}$, obtained by the light scattering method, remarkably decreases with a decrease of $W_{\text {ca }}$ below 0.15 and is expected to become zero at $W_{\text {ca }}$ of $c a$. 0.115 (i.e., Flory's $\Theta$ solvent). From values of conformation parameter and characteristic ratio of the polymer, evaluated from radius of gyration at the $\Theta$ state, the nylon 6,6 molecule is judged to be very flexible in the unperturbed state. The viscosity of the polymer solution showed specific $W_{\text {ca }}$ dependence, around $W_{\text {ca }}=0.15$. The results of the viscosity, adiabatic compressibility, IR and NMR measurements on the solvent mixtures revealed that the above $W_{\mathrm{ca}}=c a .0 .05$, mole ratio of the undissociated $\mathrm{CaCl}_{2}$ monotonically increases with $W_{\mathrm{ca}}$ and methanol molecules strongly interact with calcium chloride probably forming organometallic complex. The results of ${ }^{1} \mathrm{H}$ and ${ }^{13} \mathrm{C}$ NMR and IR measurements on the polymer solutions suggested that dissolution of nylon 6,6 in calcium chloride-methanol mixture with $W_{\text {ca }} \geqq 0.1$ is realized at least by interaction of methanol and chlorine parts in the complex with amide carbonyl and amine: In the range of $0.1 \leqq W_{\mathrm{ca}}<0.15$, selective absorption of weakly bound methanol molecules with the complex to nylon 6,6 plays an important role to determine the very compact chain conformation of the nylon 6,6 chain. Above $W_{\text {ca }}=0.15$ dissolution of nylon 6,6 takes place by direct interaction of the very bulky and metastable associate form of solvent to polymer, which brings about large expansion of the nylon 6,6 chain in the solution.
\end{abstract}

KEY WORDS Nylon 6,6 / Calcium Chloride and Methanol Mixture / Viscosity / Light Scattering / Unperturbed Chain Dimension / Adiabatic Compressibility / NMR / Metallic Halide Complex / Polymer-Solvent Complex Interaction /

An industrial importance of poly(hexamethyleneadipamide) (nylon 6,6) as a base material of fibers and engineering plastics has promoted its molecular characterization studies since 1960s. The pioneering studies were carried out by Saunders ${ }^{1,2}$ and Elias and Schumacher ${ }^{3}$ mainly using viscometric method. From reanalysis on the viscosity data reported by Elias and Schumacher, Kamide et $a l .{ }^{4}$ found that the unperturbed chain dimension $A$ of nylon 6,6 in organic and acid solvents notably differs from solvent to solvent, ranging from 0.083 to $0.114 \mathrm{~nm}$. Regarding the dissolved state of the nylon 6,6 in the solvent, Saunders $^{2,5-7}$ found that the nylon 6,6 molecular chains show a polyelectrolyte nature in aqueous acid solutions, such as aq $90 \mathrm{wt} \%$ formic acid soln and aq concd sulfuric acid 
soln, owing to protonation of the polymer amide groups. Holms et al. ${ }^{8,9}$ carried out ${ }^{1} \mathrm{H}$, ${ }^{13} \mathrm{C}$, and ${ }^{15} \mathrm{~N}$ NMR measurements on the nylon 6,6 with the number-average molecular weight $M_{n}$ of about $1.5 \times 10^{4}$ in trifluoroacetic acid (TFA), indicating that TFA molecules strongly interact with amide groups of the polymer chains. Ford and Marshall ${ }^{10}$ studied on the dissolved state of nylon 6,6 in the mixture of alcohol and inorganic salt, such as methanol/LiCl, $n$-amylalcohol/ $\mathrm{SnCl}_{4}$ and methanol/ $/ \mathrm{TiCl}_{4}$, using infrared and ultraviolet spectroscopies. They reported that some kind of coordination complex is formed between the metallic halide and the alcohol molecules and the complex interacts selectively with amide groups of the nylon 6,6. From these results in the literature, we can readily expect that the chain conformation of the nylon 6,6 polymer in the solvent is primarily determined by the interaction between polar groups of nylon 6,6 and the solvent molecules. One of the typical mixture containing inorganic halide, calcium chloride-methanol system is also a solvent for aliphatic polyamides. Using this solvent with fixed calcium chloride concentration, Nakajima and Tanaami $^{11}$ discussed the chain flexibility of nylon 6 in view of the formation of polymer-metal halide complex based on infrared and viscosity data, concluding that methanol molecules associate with dissociated calcium and chloride ions leading to coordination complex, and this complex affects the short-range interference in the nylon 6 chain conformation. However, they did not investigate the detailed structure of the solvent complex as a function of the component of the mixture, accordingly the chain conformation of the polyamide. In addition, the difference in hydrogen bonding nature between nylon 6 and nylon 6,6 may influence on their solution properties, especially in such complex forming mixed solvent system.

In this study, an attempt was made to disclose chain conformation of the nylon 6,6 in the mixtures of calcium chloride-methanol using light scattering method, which has never been applied to this polymer solution successfully except for determination of the molecular weight,${ }^{1-3}$ and to elucidate the dissolved state of the nylon 6,6 in terms of the interaction between polymer and calcium chloride--methanol complex.

\section{EXPERIMENTAL}

\section{Materials}

Nylon 6,6 (Asahi Chemical Industry Co., Tokyo), polymerized by polycondensation method from hexamethylenediamine and adipic acid, was used as a starting sample (code PC1). The sample PC1 was subjected to solid phase polymerization at $220 \pm 10^{\circ} \mathrm{C}$ under purging of nitrogen gas with a flow rate of $400 \mathrm{~cm}^{3} \mathrm{~min}^{-1}$ for $1 \mathrm{~h}$. The limiting viscosity number $[\eta]$ of the sample obtained thus (code SP1) and the sample PC1 was determined from Huggins plots using aq $98 \%$ sulfuric acid soln as solvent at $25^{\circ} \mathrm{C}$. The viscosity-average molecular weight $M_{v}$ was estimated through the following Mark-Houwink-Sakurada ${ }^{4}$ equation to be $1.55 \times 10^{5}$ for the sample SP1 and $3.6 \times 10^{4}$ for the sample PC1.

$$
[\eta]=6.3 \times 10^{-2} M_{w}^{0.73}\left(\mathrm{~cm}^{3} \mathrm{~g}^{-1}, 25^{\circ} \mathrm{C}\right)
$$

where $M_{w}$ is the weight-average molecular weight.

\section{Solution Preparation}

The mixture of calcium chloride and methanol was prepared by putting $0.22-0.25 \mathrm{~g}$ of anhydrous calcium chloride (guaranteed grade; the minimum $\mathrm{CaCl}_{2}$ assay $95 \%$; the maximum content of metals, such as iron, aluminum and barium, ca. $0.008 \%$; Kishida Chemical Co., Osaka) into $0.78-0.75 \mathrm{~g}$ of distilled methanol. Hereafter, weight fraction of $\mathrm{CaCl}_{2}$ in the mixture is termed as $W_{\mathrm{ca}}(\mathrm{w} / \mathrm{w})$. The sample PC1 was swollen for one day in the mixture with $W_{\text {ca }}$ ranging from 0.22 to 0.25 at room temperature and then dissolved at 
$80^{\circ} \mathrm{C}$. In order to determine the lower limit of $W_{\text {ca }}$ to be capable of dissolving the nylon 6,6 , the methanol was added dropwise to the sample PC1 solution with $W_{\text {ca }}=0.20$ until the solution started to reveal turbidity. $W_{\text {ca }}$ determined thus was about 0.10 .

\section{Light Scattering}

Refractive index $n_{0}$ of the solvent mixture with $W_{\text {ca }}=0.125-0.20$ was measured by Abbe refractometer with an incident beam wave length $\lambda_{0}$ of $633 \mathrm{~nm}$ at $40^{\circ} \mathrm{C}$.

The sample $\mathrm{PCl}$ was dissolved in the mixture of $W_{\text {ca }}=0.125-0.20$ at polymer concentration $c\left(\mathrm{~g} \mathrm{~cm}^{-3}\right)$ of $(1-5) \times 10^{-3}$. The solution with $c=4.8 \times 10^{-3}$ and $W_{\text {ca }}=0.20$ was dialyzed using a commercially available cellulose membrane (Union Carbide Co., U.S.A.). Donnan membrane equilibrium was attained after 7 days dialysis. The specific refractive index increment at constant $W_{\text {ca }}\left[(\mathrm{d} n / \mathrm{d} c)_{W_{\text {ca }}}\right]$ for the undialyzed solutions and at constant chemical potential of $\mathrm{CaCl}_{2}\left[(\mathrm{~d} n / \mathrm{d} c)_{\mu}\right]$ for the dialyzed solution was measured using differential refractometer type DR4 (Shimadzu, Kyoto) at $40^{\circ} \mathrm{C}$ with $\lambda_{0}$ of $633 \mathrm{~nm}$. The solutions for the light scattering measurements were filtered through membrane made of polytetrafluoroethylene (Sumitomo Denko Co., Tokyo) with pore size of $0.1-0.45 \mu \mathrm{m}$, followed by direct pouring into the measurement cell. The intensity of scattered light was recorded on the light scattering apparatus, DLS-700 manufactured by Otsuka Electronics (Osaka) with $\lambda_{0}$ of $633 \mathrm{~nm}$ at $40 \pm 0.1^{\circ} \mathrm{C}$. The data were analyzed according to Zimm's procedure.

\section{Viscosity Measurement}

The viscosity of the solvent mixture with $W_{\text {ca }}$ of $0-0.225$ and the sample SP1 solution with $W_{\text {ca }}=0.10-0.20$ was measured using Ubbelohde type viscometer at $40 \pm 0.05^{\circ} \mathrm{C}$. [ $\left.\eta\right]$ and Huggins constant $k^{\prime}$ for the polymer solution were estimated from Huggins plot as an intercept at $c=0$ and from a slope near $c=0$, respectively.

\section{Adiabatic Compressibility}

Sonic velocity $V$ of the solvent mixture with $W_{\text {ca }}=0.001-0.20$ was measured using Nunisonics model 6080 Concentration Analyzer (MAPCO Inc., U.S.A.). The solution cell was immersed in water bath thermostatted at $40 \pm 0.002^{\circ} \mathrm{C}$. Adiabatic compressibility $\beta$ of the mixture was evaluated through the relation:

$$
\beta=\frac{1}{\rho V^{2}}
$$

where $\rho$ is the density of the solvent mixture. The number of solvated solvent molecules to a solute molecule $s$ was estimated according to Passynsky's equation ${ }^{12,13}$ :

$$
s=\frac{M}{m_{\mathrm{s}}}\left(1-\frac{\beta}{\beta_{0}}\right) \frac{\left(100-W_{\mathrm{ca}}\right)}{W_{\mathrm{ca}}}
$$

Here $M$ and $m_{\mathrm{s}}$ are molecular weight of solute and solvent molecules, respectively. $\beta_{0}$ is $\beta$ of the solvent. $s$ of the methanol was estimated in the range from $W_{\text {ca }}=0.001$ to 0.20 through eq 3 .

\section{Nuclear Magnetic Resonance (NMR)}

$\mathrm{CaCl}_{2}$ and deuterated methanol $\left(\mathrm{CD}_{3} \mathrm{OD}\right.$, Aldrich Chemical Co., Japan) mixture with $\mathrm{CaCl}_{2}$ weight fraction of $0.087-0.184$, corresponding to $W_{\text {ca }}=0.10-0.20$, was prepared. Following the procedure described before, $0.02 \mathrm{~g}$ of the sample $\mathrm{PCl}$ was dissolved in $1 \mathrm{~cm}^{3}$ of each mixture except for one with $W_{\text {ca }}=0.1$. Each mixture and the solution prepared were put into a sample probe with $5 \mathrm{~mm}$ diameter, together with tetramethylsilane as internal standard. ${ }^{1} \mathrm{H}$ and ${ }^{13} \mathrm{C}$ NMR spectra were recorded on NMR-FX200 (JEOL, Tokyo) at $40^{\circ} \mathrm{C}$ under the following conditions: Spectrum width, $2 \mathrm{kHz}$ for ${ }^{1} \mathrm{H} \mathrm{NMR}, 10 \mathrm{kHz}$ for ${ }^{13} \mathrm{C}$ NMR; Pulse interval, 5, $4.6 \mathrm{~s}$; flip angle, $7 \mu \mathrm{s}=45^{\circ}, 6.5 \mu \mathrm{s}=45^{\circ}$; Number of accumulation, $8300-700$ times.

CP/MAS ${ }^{13} \mathrm{C}$ NMR measurement on the sample $\mathrm{PCl}$ was performed in the solid state using NMR-FX200 at $120^{\circ} \mathrm{C}$ under the fol- 
lowing pulse conditions: spectrum width, 20 $\mathrm{kHz}$; pulse interval, $5 \mathrm{~s}$; flip angle, $5.5 \mu \mathrm{s}=90^{\circ}$; cross-polarization contact time, $2 \mathrm{~ms}$; number of accumulation, 512 times.

\section{Infrared Spectroscopy (IR)}

Nylon 6,6 film was prepared from formic acid solution of the sample PC1 by solvent cast method followed by air drying. The air-dried film, the sample PC1 solution with $c=0.01$ and $W_{\text {ca }}=0.125-0.2$, and the solvent mixture with $W_{\text {ca }}=0.125-0.2$ were sandwiched between two transparent plates made of KRS. IR spectra were recorded on a spectrometer model JIS-3505 FT-IR (JEOL, Japan). Differential spectra of nylon 6,6 solution and solvent mixture were obtained by subtracting IR spectrum of the solvent-mixture using absorbance at $1954.5 \mathrm{~cm}^{-1}$ as standard.

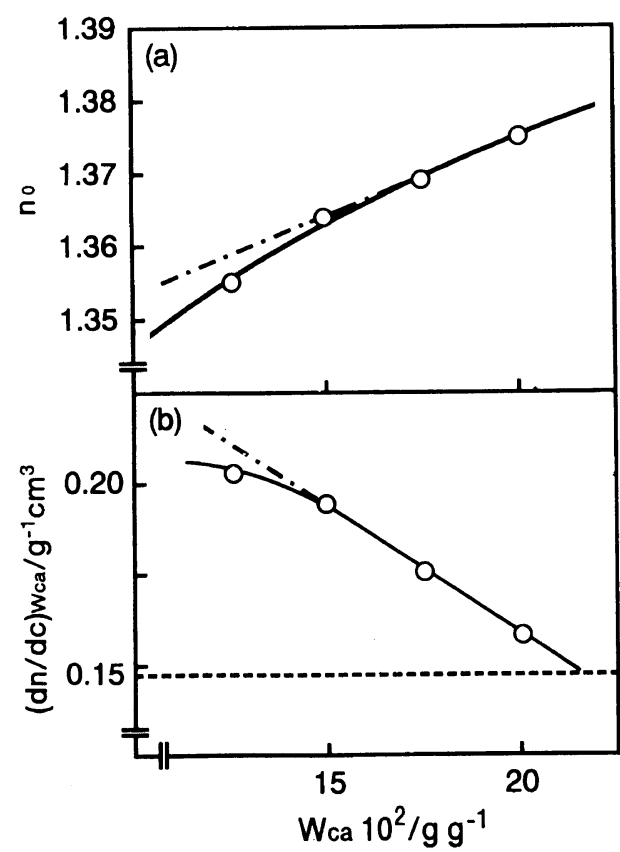

Figure 1. Refractive index $n_{0}$ of the mixture of calcium chloride and methanol (a) and specific refractive index increment at constant $W_{\mathrm{ca}}\left[(\mathrm{d} n / \mathrm{d} c)_{W_{\mathrm{ca}}}\right]$ for the undialyzed solutions (solid line) and at constant chemical potential of $\mathrm{CaCl}_{2}\left[(\mathrm{~d} n / \mathrm{d} c)_{\mu}\right]$ for the dialyzed nylon 6,6 solution (broken line) against $\mathrm{CaCl}_{2}$ soln. with $W_{\mathrm{ca}}=0.2$ (b) at $40^{\circ} \mathrm{C}$ plotted against calcium chloride concentration $W_{\text {ca }}$.

\section{RESULTS AND DISCUSSION}

$n_{0}$ of the solvent mixture and $(\mathrm{d} n / \mathrm{d} c)_{W_{\mathrm{ca}}}$ of the undialyzed polymer solution is plotted against $W_{\mathrm{ca}}$ in Figure 1a and $\mathrm{b}$, respectively. $n_{0}$ and $(\mathrm{d} n / \mathrm{d} c)_{W_{\text {ca }}}$ (solid line) monotonically change with an increase of $W_{\text {ca }}$, while a downward deviation at $W_{\mathrm{ca}}=c a .0 .15$ was observed for both plots. $(\mathrm{d} n / \mathrm{d} c)_{\mu}$ of the dialyzed solution is shown by a broken line in Figure $1 \mathrm{~b}$, for convenience.

Figure $2 \mathrm{a}$ and $\mathrm{b}$ representatively depict Zimm plots of the sample PC1 solutions with $W_{\text {ca }}=0.20$ before and after dialysis. Both plots show little distortion even at low scattering angle $\theta$, indicating that the solutions prepared were almost free from any contamination of dust and/or gel-like materials. From the plots of the undialyzed solutions, we estimated the apparent weight-average molecular weight $M_{w}{ }^{*}$, the apparent second virial coefficient $A_{2}{ }^{*}$ and $z$-average radius of gyration $\left\langle S^{2}\right\rangle_{z}{ }^{1 / 2}$,

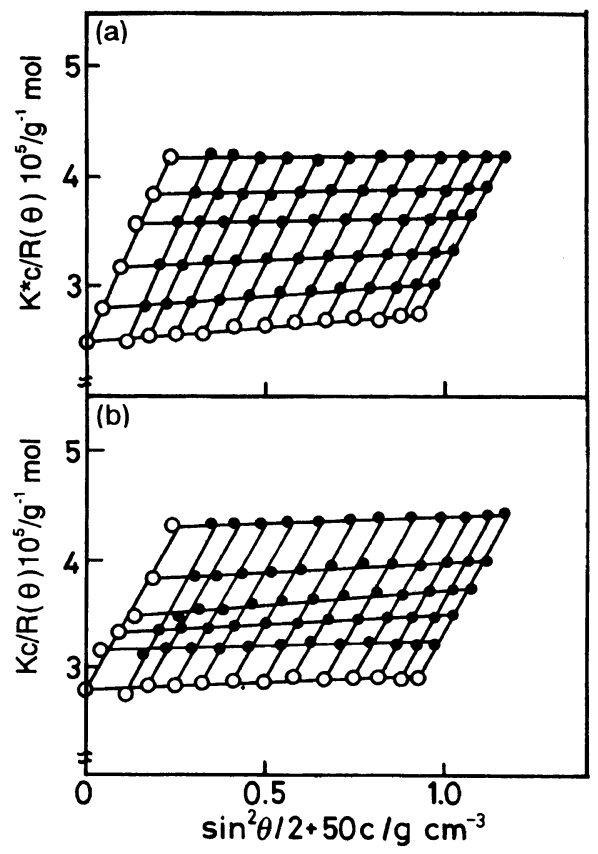

Figure 2. Zimm plots of nylon 6,6 (sample code PC1) solutions with $W_{\mathrm{ca}}=20 \%$ at $40^{\circ} \mathrm{C}$. Undialyzed (a) and dialyzed (b). 
Table I. Results on the light scattering measurements on undialyzed and dialyzed nylon 6,6 (the sample code $\mathrm{PCl}$ ) in mixture of calcium chloride and methanol with calcium concentration $W_{\text {ca }}$ ranging from 12.5 to $20 \%$ at $40^{\circ} \mathrm{C}$ and expansion factor $\alpha_{\mathrm{s}}{ }^{\mathrm{a}}$

\begin{tabular}{|c|c|c|c|c|c|c|}
\hline$W_{\mathrm{ca}}$ & $M_{w}^{*} \times 10^{-4}$ & $M_{w} \times 10^{-4}$ & $A_{2}{ }^{*} \times 10^{3}$ & $A_{2} \times 10^{3}$ & $\left\langle S^{2}\right\rangle_{z}^{1 / 2} \times 10^{6}$ & \\
\hline$\%$ & $\mathrm{~g} \mathrm{~mol}^{-1}$ & $\mathrm{~g} \mathrm{~mol}^{-1}$ & $\mathrm{~mol} \mathrm{~cm}{ }^{3} \mathrm{~g}^{-2}$ & $\mathrm{~mol} \mathrm{~cm}^{3} \mathrm{~g}^{-2}$ & $\mathrm{~cm}$ & \\
\hline 12.5 & 2.54 & - & 1.00 & 0.56 & 0.69 & 1.08 \\
\hline 15.0 & 2.86 & - & 1.47 & 9.53 & 0.91 & 1.42 \\
\hline 17.5 & 3.33 & - & 1.57 & 1.19 & 1.16 & 1.81 \\
\hline 20.0 & 3.76 & - & 1.59 & 1.36 & 1.29 & 2.01 \\
\hline Dialyzed & - & 4.41 & - & 1.20 & 1.19 & 1.86 \\
\hline
\end{tabular}

a $M_{w}{ }^{*}, M_{w}$, the apparent and true weight-average molecular weight; $A_{2}{ }^{*}, A_{2}$, the apparent and true second virial coefficient; $\left\langle S^{2}\right\rangle_{z}{ }^{1 / 2}$, the $z$-average radius of gyration.

which are summarized in Table I.

$M_{w}{ }^{*}$ and $M_{w}$ relate to the reduced scattering intensity $R(\theta)$ as follows ${ }^{14}$ :

$$
\begin{aligned}
& {\left[\frac{K^{*} c}{R(\theta)}\right]_{c=0}=\left[M_{w}{ }^{*} P(\theta)\right]^{-1}} \\
& {\left[\frac{K c}{R(\theta)}\right]_{c=0}=\left[M_{w} P(\theta)\right]^{-1}}
\end{aligned}
$$

where $P(\theta)$ is a scattering function and $K^{*}$ and $K$ are optical constants given as follows:

$$
\begin{gathered}
K^{*}=\frac{2 \pi^{2} n_{0}{ }^{2}}{\lambda_{0}{ }^{4} N_{\mathrm{A}}}\left(\frac{\mathrm{d} n}{\mathrm{~d} c}\right)_{W_{\mathrm{ca}}}^{2} \\
K=K^{*}\left[\frac{\left(\frac{\mathrm{d} n}{\mathrm{~d} c}\right)_{\mu}}{\left(\frac{\mathrm{d} n}{\mathrm{~d} c}\right)_{W_{\mathrm{ca}}}}\right]^{2}
\end{gathered}
$$

Here $N_{\mathrm{A}}$ is the Avogadro's number.

The second virial coefficient $A_{2}$ is described in terms of $M_{w}{ }^{*}, M_{w}$ and $A_{2}{ }^{*}$ as follows ${ }^{14}$ :

$$
A_{2}=\frac{M_{w}^{*}}{M_{w}} A_{2}{ }^{*}
$$

Substitution of $M_{w}{ }^{*}, M_{w}$ and $A_{2}{ }^{*}$ obtained experimentally into eq 6 gives us $A_{2}$.

Selective adsorption parameter $\xi_{\mathrm{a}}$ is defined as follows ${ }^{14}$ :

$$
\xi_{\mathrm{a}}=\left(\sqrt{\frac{M_{w}^{*}}{M_{w}}-1}\right)^{\rho_{\mathrm{soln}}\left(\frac{\mathrm{d} n}{\mathrm{~d} c}\right)_{W_{\mathrm{ca}}}}
$$

where $\rho_{\text {soln }}$ and $\rho_{\text {ca }}$ are the density of the polymer solution and calcium chloride in the mixture, respectively. In this study, the density of the solvent mixture $\rho$ determined using picnometer at $40^{\circ} \mathrm{C}$ was used as the value of $\rho_{\text {soln }}$, because the polymer solutions prepared here were sufficiently dilute and $\rho_{\text {ca }}$ was assumed to be unity.

Figure $3 \mathrm{a}, \mathrm{b}$ and $\mathrm{c}$ show $W_{\mathrm{ca}}$ dependence of $M_{w}{ }^{*}, \xi_{\mathrm{a}}(\mathrm{a}), A_{2}{ }^{*}, A_{2}$ (b) and $\left\langle S^{2}\right\rangle_{z}{ }^{1 / 2}$ (c) for the sample $\mathrm{PCl}$. In the whole range of $W_{\text {ca }}$ investigated, $\xi_{\mathrm{a}}$ is negative due to the relation of $M_{w}{ }^{*}<M_{w}$ (broken line) and increases linearly with $W_{\text {ca }}$, indicating that methanol molecules selectively solvate to the polymer chain and amount of the solvated molecules decreases with an increase of $W_{\text {ca }}$. Details of interaction between polymer and solvent molecules are discussed latter. $A_{2}{ }^{*}$ and $A_{2}$ remarkably increase with $W_{\text {ca }}$ in the range $W_{\text {ca }}<0.15$ and $A_{2}{ }^{*}$ seems to approach an asymptotic value at $W_{\text {ca }} \geqq 0.175$. These $W_{\text {ca }}$ dependence of $\xi_{\mathrm{a}}, A_{2}{ }^{*}$ and $A_{2}$ suggest at least that adsorption behavior of the solvent mixture onto nylon 6,6 is different below and above $W_{\text {ca }}=0.15-0.175 . A_{2}=0$ is realized at $W_{\mathrm{ca}}=$ 


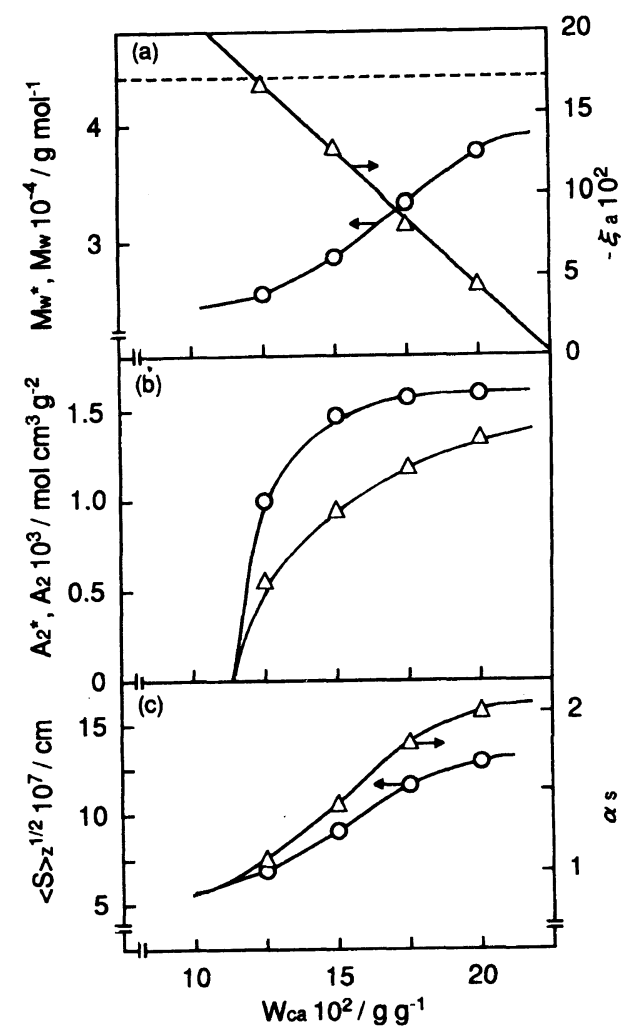

Figure 3. The apparent and true weight-average molecular weight $M_{w}{ }^{*}, M_{w}$ (dotted line), adsorption parameter $\xi_{\mathrm{a}}$ (broken line) (a), the apparent and true second virial coefficient $A_{2}$ (b) and $z$-average radius of gyration $\left\langle S^{2}\right\rangle_{z}{ }^{1 / 2}$ (c) plotted against calcium chloride concentration $W_{\text {ca }}$.

ca. 0.115 , indicating that the calcium chloridemethanol mixture with $W_{\text {ca }}$ of about 0.115 is expected to be the Flory's $\Theta$ solvent for nylon 6,6 at $40^{\circ} \mathrm{C} .\left\langle S^{2}\right\rangle_{z}{ }^{1 / 2}$ at $A_{2}=0$, i.e., the radius of gyration at unperturbed state $\left\langle S^{2}\right\rangle_{z, 0}^{1 / 2}$, is $6.4 \mathrm{~nm}$ for this sample. From $\left\langle S^{2}\right\rangle_{z, 0}^{1 / 2}$ value, the linear expansion factor $\alpha_{s}$, defined as $\alpha_{\mathrm{s}}=\left\langle S^{2}\right\rangle_{z}{ }^{1 / 2} /\left\langle S^{2}\right\rangle_{z, 0}^{1 / 2}$, is estimated (triangle in Figure $3 \mathrm{c}$ ). Owing to the increase of the interaction between polymer and solvent molecules as discussed later, the nylon 6,6 chains expand with $W_{\text {ca }}$, approaching to an asymptotic value near $W_{\text {ca }}=0.2$.

The unperturbed chain dimension $A$ of the Gaussian chain is written as a function of the radius of gyration as follows:

$$
A=\sqrt{\frac{6\left\langle S^{2}\right\rangle_{w, 0}}{M_{w}}}
$$

Here, $\left\langle S^{2}\right\rangle_{w, 0}^{1 / 2}$ is the weight-average radius of gyration of the polymer chain at the unperturbed state and relates to $\left\langle S^{2}\right\rangle_{z, 0}^{1 / 2}$, when molecular weight distribution function (MWDF) of the polymer is Schultz-Zimm type through the following equation:

$$
\left\langle S^{2}\right\rangle_{w, 0}^{1 / 2}=\sqrt{\frac{h+1}{h+2}}\left\langle S^{2}\right\rangle_{z, 0}^{1 / 2}
$$

where

$$
h=\left(\frac{M_{w}}{M_{n}}-1\right)^{-1}
$$

$M_{n}$ is the number-average molecular weight. Hattori et al. ${ }^{15}$ carried out successive precipitation fractionation of the sample PC1, using a mixture of phenol/tetrachloroethane $(4 / 6 \mathrm{w} / \mathrm{w})$ as a solvent and $n$-heptane as a coagulant, finding that MWDF estimated by the cumulative method can be approximated to be Schultz-Zimm type with $M_{w} / M_{n}=2$ with high accuracy.

Substitution of $M_{w}$ and $\left\langle S^{2}\right\rangle_{w, 0}^{1 / 2}$, which is estimated from eq 9 and 10 , into eq 8 gives us $A$ of the nylon 6,6 to be $0.061 \mathrm{~nm}$. This value is appreciably smaller than the reported values of $A$ in various good solvents $(0.083-0.114$ $\mathrm{nm})^{4}$ and in aq $90 \%$ formic acid with $0.23 \mathrm{M}$ $\mathrm{KCl}(0.096 \mathrm{~nm})$. The latter solvent is also an another Flory's $\Theta$ solvent for the nylon 6,6 according to Saunders. ${ }^{1,2}$ Note here that all of these $A$ are determined by the viscosity methods, such as Stockmayer-Fixman ${ }^{2,3}$ and Kamide methods. ${ }^{4}$ However, both methods include two essential problems; one is uncertainty of the value of the Flory's viscosity parameter, which reportedly ranges from $2.2 \times$ $10^{23}$ to $2.87 \times 10^{23}\left(\mathrm{~cm}^{3} \mathrm{~g}^{-1}\right)$ in the literature; the other is that both methods are only applicable to the system where draining effect can be completely neglected. ${ }^{16}$ Unfortunately, for the nylon 6,6 solutions, it has never been 
Table II. Comparison of conformation parameter $\sigma$ and characteristic ratio $C_{\infty}$ of various synthetic and derivatized natural polymers determined by light scattering method in $\Theta$ solvent $^{17}$ except for the nylon 6,6

\begin{tabular}{llccc}
\hline \multicolumn{1}{c}{ Polymer } & \multicolumn{1}{c}{ Solvent } & Temp/ ${ }^{\circ} \mathrm{C}$ & $\sigma$ & $C_{\infty}$ \\
\hline Polyethylene & Bis-2-ethylhexil adipate & 145 & 2.27 & 10.3 \\
a-Polypropylene & Diphenyl ether & 145 & 1.44 & 4.15 \\
a-Poly(methyl methacrylate) & Butylchloride & 35.4 & 1.74 & 6.05 \\
Poly(vinyl acetate) & Heptane/3-methyl-2-butanone & 25 & 2.24 & 10.0 \\
a-Polystyrene & Cyclohexane & 34 & 2.28 & 10.4 \\
Amylose tricarbanilate & Dioxan/methanol & 20 & 11.7 & - \\
Cellulose triacetate & Cyclohedxanol & 73 & 2.52 & - \\
Nylon 6,6 & Calcium chloride/methanol & 40 & 1.12 & 4.29 \\
\hline
\end{tabular}

a Weight ratio of calcium chloride to total weight of mixture $W_{\mathrm{ca}}=11.5 \%$.

proved whether the effect is negligible or not. From these reasons, the $A$ values of the nylon 6,6 evaluated hitherto is considered not to be reliable.

Conformation parameter $\sigma$ and characteristic ratio of the polymer chain with infinite molecular weight $C_{\infty}$, defined in eq 11 and 12 respectively, are able to be evaluated from $A$.

$$
\begin{gathered}
\sigma=\frac{A}{A_{\mathrm{f}}} \\
C_{\infty}=\frac{A_{\infty}^{2} M_{\mathrm{b}}}{l^{2}}
\end{gathered}
$$

Here, $A_{\mathrm{f}}$ is $A$ of freely rotating chain to be $0.0545 \mathrm{~nm}$ for the nylon 6,$6 ; A_{\infty}, A$ at infinite molecular weight; $M_{\mathrm{b}}$, the molecular weight of skeletal bond; $l$, root mean square length of a bond constituting a polymer chain. If we assume that the unperturbed chain dimension of nylon 6,6 polymeric chain is independent of molecular weight in the region of $M_{w}$ more than $4 \times 10^{4}$, we can obtain $\sigma$ and $C_{\infty}$ to be 1.12 and 4.29, respectively. In Table II, $\sigma$ and $C_{\infty}$ of the various polymers estimated from the data of light scattering in $\Theta$ solvent picked up from ref 17 are listed. Inspection of the table shows that the polymers with small $\sigma$ and $C_{\infty}$, for example less than 2 and 10 , respectively are a few and the nylon 6,6 is categorized as very flexible polymer.

In order to clarify the characteristic features of the nylon 6,6 solutions, such as remarkable decrease of the second virial coefficient below $W_{\text {ca }}=0.15, \Theta$ solvent at $W_{\text {ca }}=c a .0 .11$, and very high chain flexibility of nylon 6,6 in the unperturbed state, structure of the solvent mixture and polymer-solvent interaction in the solution were investigated in detail, at least judging from the values of chain conformation parameters at $\Theta$ state.

For the methanol- $\mathrm{CaCl}_{2}$ system at $40^{\circ} \mathrm{C}$, a ratio of the specific viscosity $\eta_{\mathrm{sp}}$ to root of the concentration of $\mathrm{CaCl}_{2}\left(c_{\mathrm{CA}} ; \mathrm{g} \mathrm{cm}^{-3}\right)$ is plotted against $c_{\mathrm{CA}}^{1 / 2}$ in Figure 4. Regarding an electrolyte solution in dilute resume, where perfectly dissociated ions and solvent interact together only through electrostatic Coulomb force, the specific viscosity $\eta_{\text {sp }}$ of the solution is expressed as a function of the concentration of solute molecules $c\left(\mathrm{~g} \mathrm{~cm}^{-3}\right)$ as follows ${ }^{18}$ :

$$
\frac{\eta_{\mathrm{sp}}}{\sqrt{c}}=a+b \sqrt{c}
$$

where coefficients $a$ and $b$ are the parameters representing specific interaction, such as ionion and ion-solvent molecule, respectively. In the region of $c_{\mathrm{CA}}^{1 / 2}$ lower than $0.2\left(c_{\mathrm{CA}}=0.040\right.$, $W_{\text {ca }}=0.048$ ) (indicated by filled arrow), in the Figure 4 , the relationship between the ratio $\eta_{\mathrm{sp}} / c_{\mathrm{CA}}^{1 / 2}$ of the methanol- $\mathrm{CaCl}_{2}$ system and $c^{1 / 2}$ is simply expressed by a linear line with $a=0$ and positive $b$, indicating that interaction 


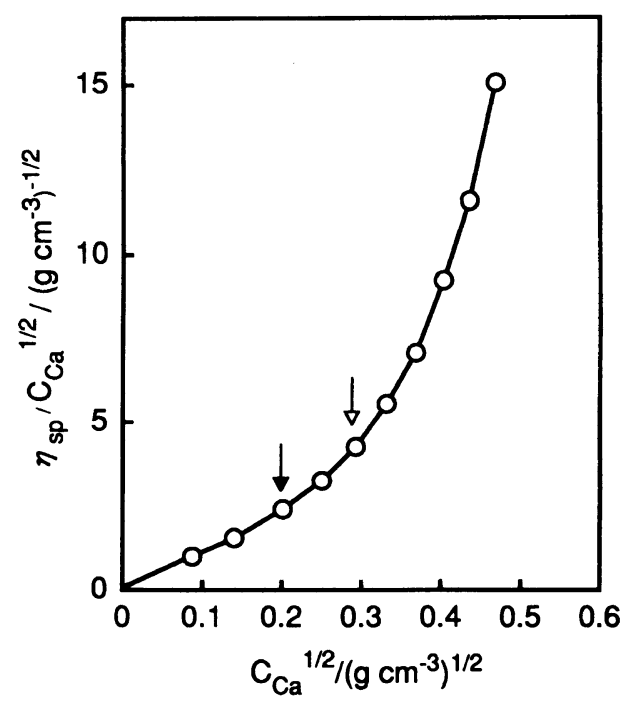

Figure 4. Ratio of specific viscosity $\eta_{\text {sp }}$ to root of calcium concentration $C_{\mathrm{CA}}, \eta_{\mathrm{sp}} / C_{\mathrm{CA}}^{1 / 2}$, of the mixture of methanol and calcium chloride at $40^{\circ} \mathrm{C}$ plotted against $C_{\mathrm{CA}}^{1 / 2}$.

between solute molecules is almost negligible, and the ions of calcium and chloride strongly interact to methanol molecules. Above $c_{\mathrm{CA}}^{1 / 2}=$ 0.2 , data of $\eta_{\mathrm{sp}} / c_{\mathrm{CA}}^{1 / 2}$ reveal remarkable upward departure from the line as observed for other salts of class in methanol ${ }^{19}$ and sodium and potassium chlorides and bromides in $\mathrm{N}$ methylformamide. ${ }^{20}$ That type of derivation from Jones and Dole's equation for the various salts in aqueous and non aqueous solvents was reasonably explained by occurrence of ion association. ${ }^{21}$ So in the present mixed solvent system, association between $\mathrm{Ca}^{2+}, \mathrm{Cl}^{-}$ions and methanol seems to occur above $c_{\mathrm{CA}}=0.04$ $\left(W_{\mathrm{ca}}=0.047\right)$ and mole ratio of the associating ions to dissociating one monotonically increases with an increase of content of $\mathrm{CaCl}_{2}$ in the mixture. In fact, at very high $\mathrm{CaCl}_{2}$ concentration ( $\left.W_{\mathrm{ca}}>0.40\right)$, coordination complex in the form of $\left[\mathrm{Ca}\left(\mathrm{CH}_{3} \mathrm{OH}\right)_{4}\right]^{2+}\left(\mathrm{Cl}^{-}\right)_{2}{ }^{22}$, is isolated as solid and has been industrially utilized as a starting material for purification of methanol. ${ }^{23}$ It should be pointed out that $W_{\text {ca }}$ value of onset of the deviation is far lower than the minimum $W_{\text {ca }}$ of the mixed solvent capable to dissolve the nylon 6,6 (indicated by

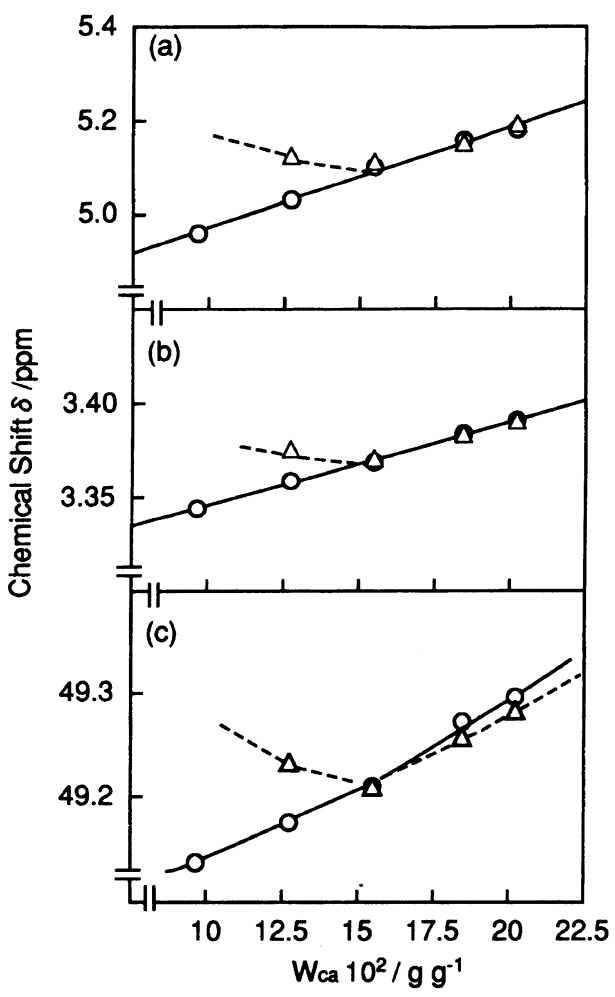

Figure 5. Calcium chloride concentration $W_{\text {ca }}$ dependence of chemical shift of hydroxy proton $\delta_{\mathrm{OH}}(\mathrm{a})$, methyl proton $\delta_{\mathrm{CH}_{3}}$ (b) and methyl carbon $\delta_{\mathrm{C}}$ (c) of methanol molecule in solvent mixture (circle) and in nylon 6,6 solution (triangle).

unfilled arrow). From these facts the complex of methanol associated with $\mathrm{CaCl}_{2}$ is considered to play an important role to dissolution of the solid nylon 6,6 into the mixture.

Figure 5a, b, c show $W_{\text {ca }}$ dependence of chemical shift, determined by ${ }^{1} \mathrm{H}$ and ${ }^{13} \mathrm{C}$ NMR spectrum, of hydroxy proton $\delta_{\mathrm{OH}}(\mathrm{a})$, methyl proton $\delta_{\mathrm{CH}_{3}}$ (b) and methyl carbon $\delta_{\mathrm{C}}$ (c) of undeuterated methanol molecules in the solvent mixture (circle) with $W_{\text {ca }}$ ranging from 0.095 to 0.20 . The hydrogen and carbon atoms of the methanol molecules become magnetically deshielded by an increase of the concentration of $\mathrm{CaCl}_{2}$. Note here that effect of metal atoms included in the $\mathrm{CaCl}_{2}$ reagent as impurity on the chemical shift can be ignored, because the assay of the metal atoms is 
negligibly small. Considering strong electron acceptor nature of calcium ions, the concurrent deshielding trend of three kinds of atoms for methanol molecule with increasing $W_{\text {ca }}$ seems to be reasoned only when calcium atom coordinates with oxygen in methanol molecules, thus indicating a selective association of methanol molecules with undissociated $\mathrm{Ca}$ ions, rather than chloride ions.

$\delta_{\mathrm{OH}}, \delta_{\mathrm{CH}_{3}}$, and $\delta_{\mathrm{C}}$ of undeuterated methanol molecules in the nylon 6,6 solution are represented by triangle in Figure 5. An addition of nylon 6,6 polymer to the mixture brings about the lower magnetic field shift of the hydrogen and carbon atoms of methanol in the lower $W_{\text {ca }}$ region than 0.15 , while the effect of the polymer to the methanol molecules is almost ignored in higher $W_{\text {ca }}$ region. This again strongly suggests the different dissolved state or dissolving mechanism of nylon 6,6 in methanol- $\mathrm{CaCl}_{2}$ below and above $W_{\mathrm{ca}}=c a$. 0.15 . Seeing from solvent mixture side, the dissolved state of methanol in the nylon 6,6 solution with low $W_{\text {ca }}$ should become equal to that in the solution with $W_{\mathrm{ca}}>0.15$.

Figure 6 shows number of solvated methanol $s$ in $\mathrm{CaCl}_{2}$-methanol mixture as a function of $W_{\text {ca }} s$ decreases almost linearly with an increase in $W_{\text {ca }}$ except for near $W_{\text {ca }}=0$, showing no $W_{\text {ca }}$ specificity. At $W_{\text {ca }}=c a .0 .10$ which is almost $\Theta$ solvent composition and also minimum value for dissolution of nylon 6,6 , one $\mathrm{mol}$ of $\mathrm{CaCl}_{2}$ is solvated with $7-8 \mathrm{~mol}$ of methanol. $s$ is almost $6 \mathrm{~mol} \mathrm{~mol}^{-1}$ at $W_{\mathrm{ca}}=$ $0.15-0.175$ giving an asymptotic value of $A_{2}{ }^{*}$. Interestingly, if we extrapolate the plot to $W_{\text {ca }}=0.4$ we can estimates $s=4\left(\mathrm{~mol} \mathrm{~mol}^{-1}\right)$, which can be referred to the complex from $\left[\mathrm{Ca}\left(\mathrm{CH}_{3} \mathrm{OH}\right)_{4}\right]^{2+}\left(\mathrm{Cl}^{-}\right)_{2}$ (hereafter referred to as associate form I), as described before. Of course, the residual methanol molecules are exchanging with the solvated ones. Taking this fact and the possible octa-valent coordination of $\mathrm{Ca}$ ion $^{24,25}$ into consideration, $6 \mathrm{~mol}$ of methanol may coordinate with one mol of $\mathrm{Ca}$ ion in the form, for example, $\left[\mathrm{Ca}\left(\mathrm{CH}_{3}-\right.\right.$

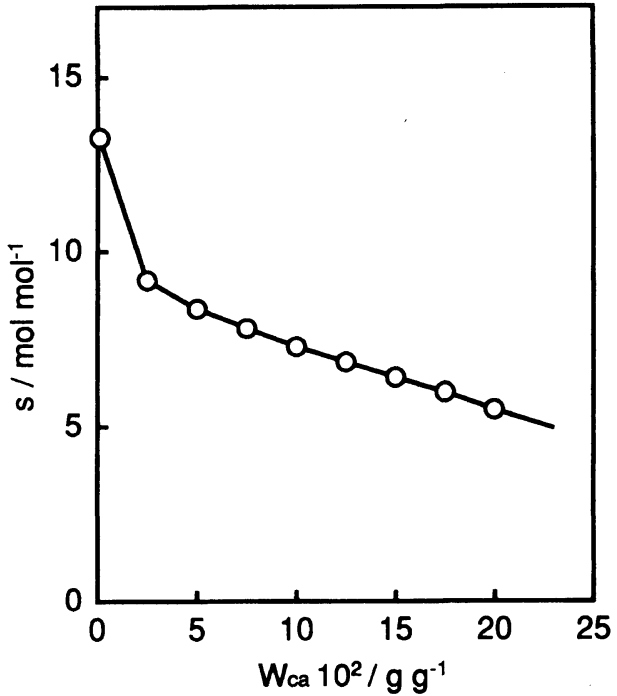

Figure 6. Calcium chloride concentration $W_{\text {ca }}$ dependence of solvating solute molecules number $s$ of the mixture of methanol and calcium chloride at $40^{\circ} \mathrm{C}$.

$\left.\mathrm{OH})_{6}\right]^{2+}\left(\mathrm{Cl}^{-}\right)_{2}$ at $W_{\text {ca }}=0.15-0.175$. Tentative structures of solvent mixture at $W_{\text {ca }}=c a$. $0.10,0.15-0.175$, and 0.4 are illustrated as representatives in Figure 7 . Note that the structure for the mixture at $W_{\text {ca }}=c a .0 .10$ can explain the NMR results obtained when nylon 6,6 is added to the mixture if we consider that extra-solvated methanol first interacts with nylon 6,6 , being into the transition state, $\left[\mathrm{Ca}\left(\mathrm{CH}_{3} \mathrm{OH}\right)_{6}\right]^{2+}\left(\mathrm{Cl}^{-}\right)_{2}$.

Figure $8 \mathrm{a}, \mathrm{b}$ show $W_{\text {ca }}$ dependence of $[\eta]$ and $k^{\prime}$ obtained by the Huggins plots for the polymer (sample SP1) solutions. In the region of $W_{\mathrm{ca}}<0.13,[\eta]$ increases almost linearly with $W_{\text {ca }}$ and shows a plateau near $W_{\text {ca }}=0.13$ 0.175 , where the data points rather scatter, and again increases from the point of $W_{\mathrm{ca}}=0.175$. Just at the $W_{\text {ca }}$ region where the line of $[\eta]$ shows plateau, $k^{\prime}$ becomes maximum. These facts certify that the dissolution state of polymer is quite different below and above $W_{\text {ca }}=c a .0 .15-0.175$, especially the nylon 6,6 dissolves in the mixture with $W_{\text {ca }}=c a$. $0.15-0.175$ in quite specific manner.

In Figure $9,{ }^{13} \mathrm{C}$ NMR spectrum of the nylon 
(a)

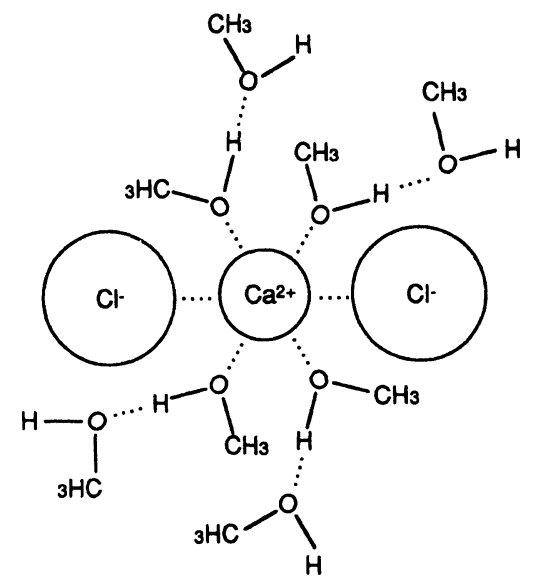

(b)

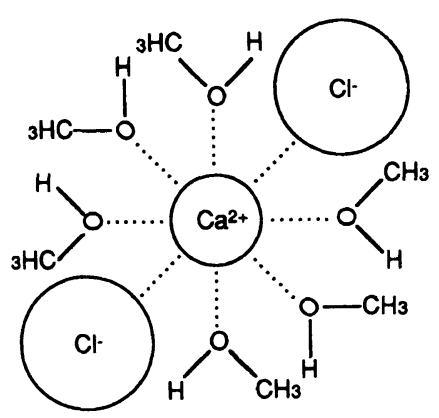

(c)

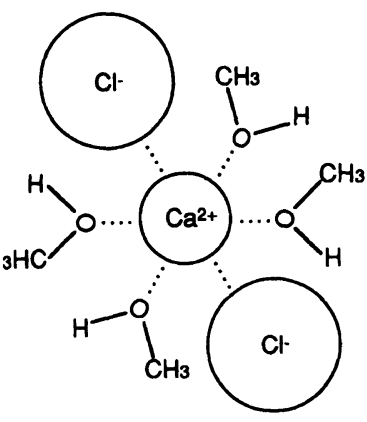

Figure 7. Schematic representation of $\mathrm{CaCl}_{2}$-methanol complex in the solvent mixture at $40^{\circ} \mathrm{C}$, (a) $0.1 \leqq$ $W_{\text {ca }} \leqq 0.15$; (b) $0.15<W_{\text {ca }} \leqq 0.175$; (c) $W_{\mathrm{ca}}=0.4$.

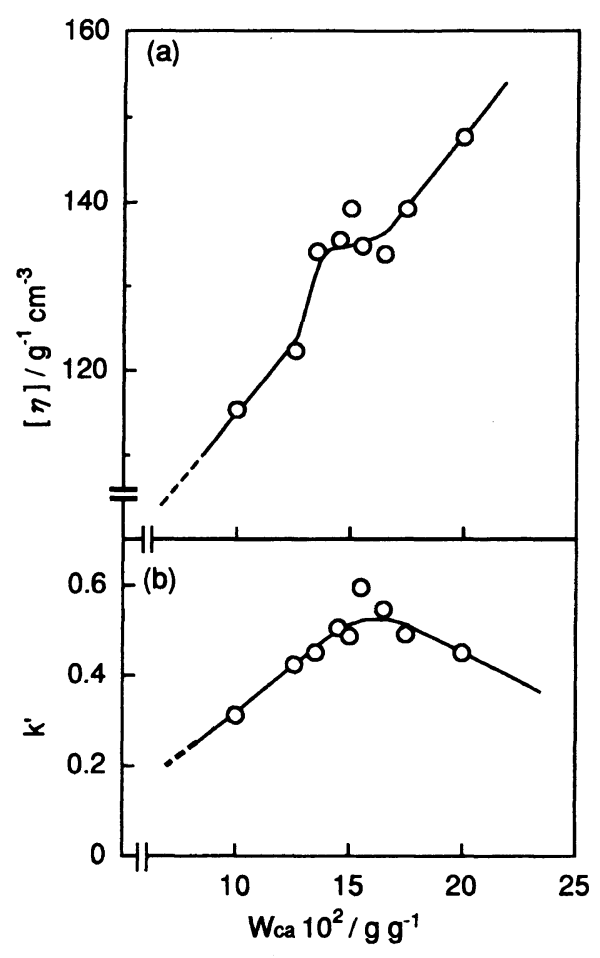

Figure 8. Limiting viscosity number $[\eta]$ (a) and Huggins constant $k^{\prime}(\mathrm{b})$ of nylon 6,6 in mixture of calcium chloride and methanol at $40^{\circ} \mathrm{C}$ plotted against calcium chloride concentration $W_{\text {ca }}$.

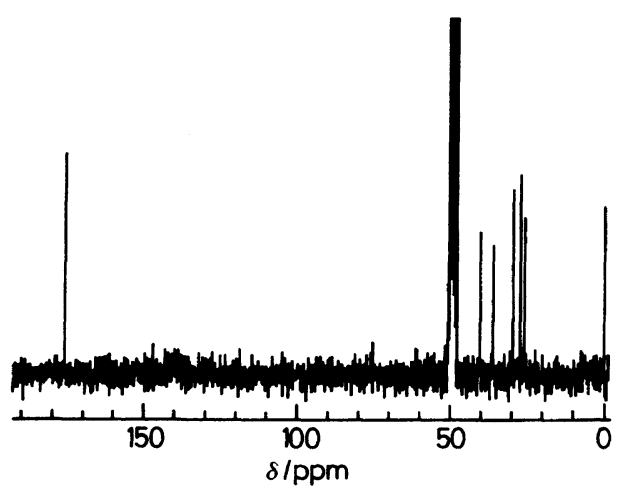

Figure 9. NMR spectra of nylon 6,6 solution with $W_{\text {ca }}=20 \%$ at $40^{\circ} \mathrm{C}$.

6,6 solutions with $W_{\text {ca }}=0.20$ is representatively shown. By referring to assignment in the literature, ${ }^{8,9}$ each peak in ${ }^{13} \mathrm{C}$ NMR spectrum of the nylon 6,6 solutions with $W_{\text {ca }}=0.20$ was ascribed as follows: Methylene carbons at $\alpha$ and $\beta$ position from amide carbonyl, $\alpha-\mathrm{C}=\mathrm{O}$, $36.184 \mathrm{ppm}, \beta-\mathrm{C}=\mathrm{O}, 25.953 \mathrm{ppm}$; methylene carbons at $\alpha$ and $\beta$ and $\gamma$ position from amide amine, $\alpha-\mathrm{NH}, 40.583 \mathrm{ppm}, \beta-\mathrm{NH}, 29.744 \mathrm{ppm}$, $\gamma-\mathrm{NH}, 27.411 \mathrm{ppm}$; amide carbonyl carbon, $176.062 \mathrm{ppm}$. Note that ${ }^{13} \mathrm{C}$ NMR peaks for $\alpha-\mathrm{NH}$ carbon and amide carbonyl carbon for nylon 6,6 solid at $120^{\circ} \mathrm{C}$ were found at 40.678 

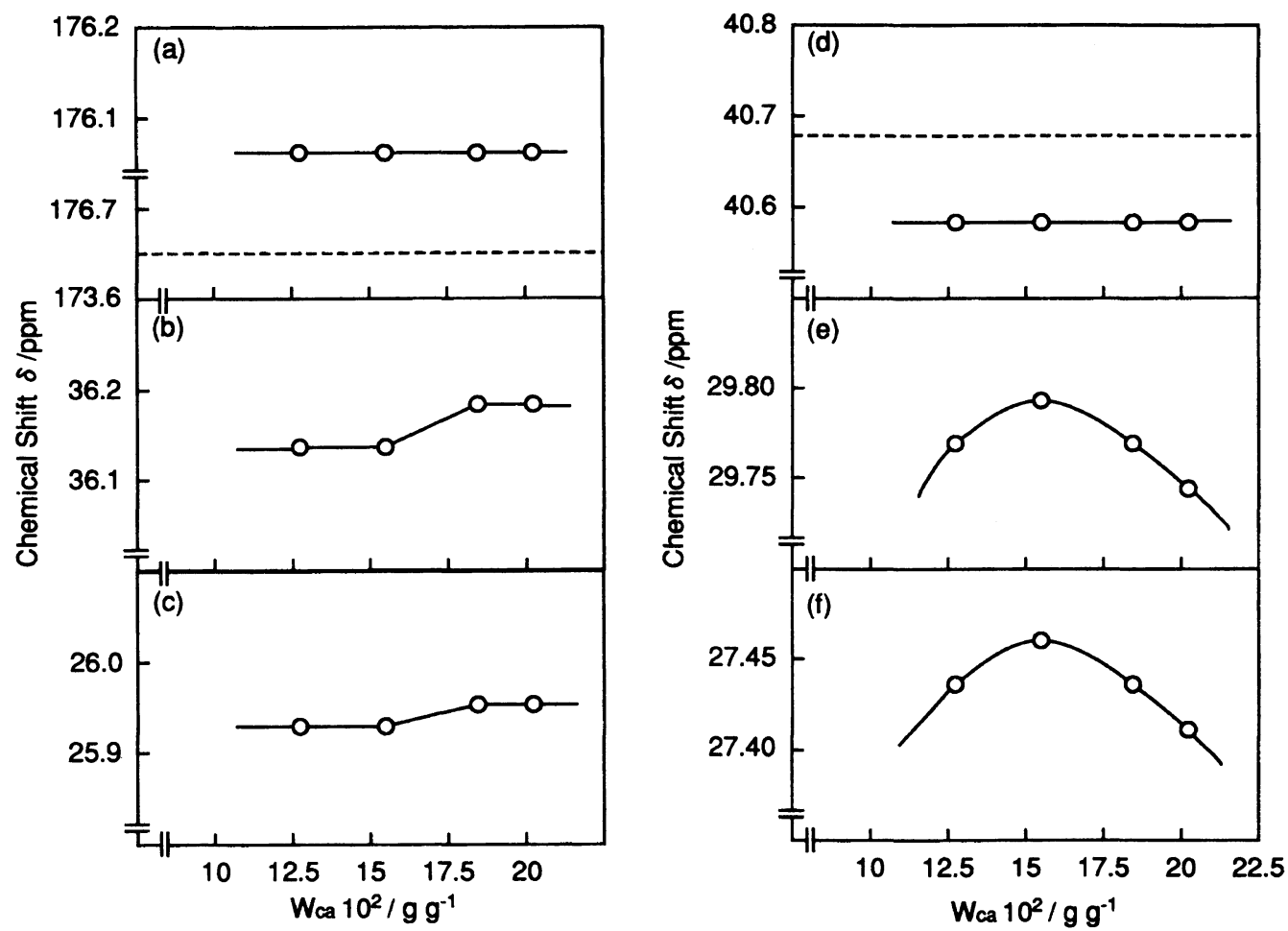

Figure 10. Calcium chloride concentration $W_{\text {ca }}$ dependence of chemical shift $\delta$ of (a) amide carbonyl carbon; (b) $\alpha-\mathrm{C}=\mathrm{O}$; (c) $\beta-\mathrm{C}=\mathrm{O}$; (d) $\alpha-\mathrm{NH}$; (e) $\beta-\mathrm{NH}$; (f) $\gamma-\mathrm{NH}$ (solid line) of nylon 6,6 in solution at $40^{\circ} \mathrm{C}$. Broken line, amide carbonyl carbon (a) and $\alpha-\mathrm{NH}$ (d) of nylon 6,6 in solid state at $120^{\circ} \mathrm{C}$.

and $173.65 \mathrm{ppm}$, respectively.

The $W_{\text {ca }}$ dependence of chemical shift of these carbons is shown in Figure 10. The chemical shift of both carbonyl carbon and $\alpha-\mathrm{NH}$ is almost independent of $W_{\text {ca }}$ (Figure $10 \mathrm{a}, \mathrm{d})$. Since carbonyl carbon peak of nylon 6,6 solid at $120^{\circ} \mathrm{C}$ shifted to considerably lower magnetic field after nylon 6,6 dissolved in the solvent mixture, electron density on carbonyl carbon is diminished by direct interaction of solvent mixture (probably hydroxyl hydrogen of methanol) on carbonyl oxygen. This prediction is supported by the results reported by Ford and Marshall, ${ }^{10}$ and Nakajima and Tanaami ${ }^{11}$ who showed by infrared spectroscopy for nylon 6,6 and nylon 6 in the calcium chloride-methanol system, that stretching frequency of the amide carbonyl group of the both polyamides obviously shifts to higher wave number side, comparing to the frequency of the nonassociated amide. Likewise, the lower magnetic field shift (ca. $0.1 \mathrm{ppm})$ of $\alpha-\mathrm{NH}$ methylene carbon from its solid to solution is significant (Figure 10d). In order to elucidate this fact we need to take some interaction of amide NH site of nylon 6,6 with solvent mixture into consideration. The independency of chemical shifts for carbonyl carbon and a-NH methylene carbon on $W_{\text {ca }}$ clearly indicates that in the dissolved state both carbonyl and amine sites in amide group of polymer should be strongly interacted with components in some associated form of solvent mixture, irrespective of the $W_{\mathrm{ca}}$ concentration investigated here. On the other hand, chemical shifts of $\beta$ - and $\gamma-\mathrm{NH}$ methylene carbons (Figure 10e, f) reconfirmed that dissolved state of polymer in $\mathrm{CaCl}_{2}$ methanol mixture with $W_{\text {ca }}=c a .0 .15$ is specific 
as postulated in Figure 8. Lowest magnetic field shifts of these methylene carbons in the above mixture with $W_{\mathrm{ca}}=c a \cdot 0.15$ could not be understood without considering direct interaction of solvent component to methylene hydrogen or long-distance deshielding effect, both brought about by the some specific coordination form of solvent mixture having a certain steric factor. In this sense, solvent mixture with $W_{\text {ca }}=0.15-0.175$ should take a distinguished coordination form from those at $W_{\text {ca }}=c a .0 .10$ and $W_{\text {ca }}>0.175$. If the octavalent coordination form shown in Figure 7 is assumed for the mixture with $W_{\text {ca }}=0.15$ 0.175 and this form is meta-stable comparing to the stable hexa-valent calcium ion form (i.e., at $W_{\text {ca }}=c a .0 .10$ and $W_{\text {ca }} \gg 0.175$ ), two extra methanol molecules solvated directly to calcium ion may interact with $\beta$ - and $\gamma-\mathrm{NH}$ methylene hydrogen not with $\alpha$-NH methylene hydrogen. The latter reason will be discussed later. Lower magnetic field shifts of $\alpha-\mathrm{C}=\mathrm{O}$ and $\beta-\mathrm{C}=\mathrm{O}$ methylene carbons (Figure $10 \mathrm{~b}$, c) in the $W_{\text {ca }}>0.175$ is easily understood by the direct interaction of hydroxyl group of methanol cooperated in some coordination form of calcium ion to amide carbonyl oxygen, leading to a mesomery effect on $\alpha$ - and $\beta-\mathrm{C}=\mathrm{O}$ methylene carbons.

The last problem left here is whether $\mathrm{NH}$ site of amide of polymer and $\mathrm{Cl}$ ions really take part in the dissolved state of polymer and this is clearly pictured in Figure 11. Infrared analysis on $\mathrm{NH}$ stretching vibration revealed that contact of the polymer with solvent mixture with $W_{\text {ca }} \geqq 0.125$ gives a new absorption band at $2760 \mathrm{~cm}^{-1}$, which is characteristic band of cationized $\mathrm{NH}\left(\mathrm{NH}_{2}{ }^{+}\right)$stretching as pointed out by Saunders ${ }^{6}$ and Schaefgen et $a l^{26}$ and is never observed for the polymer in the solid state (Figure 11a) and split of the deformation vibration band observed at 1550 $\mathrm{cm}^{-1}$ for polymer film (broken line) ${ }^{27}$ into two peaks (Figure 11b). The latter fact denotes that at least two vibrational states of $\mathrm{NH}$ exist in the solvent mixture. Cationized form of

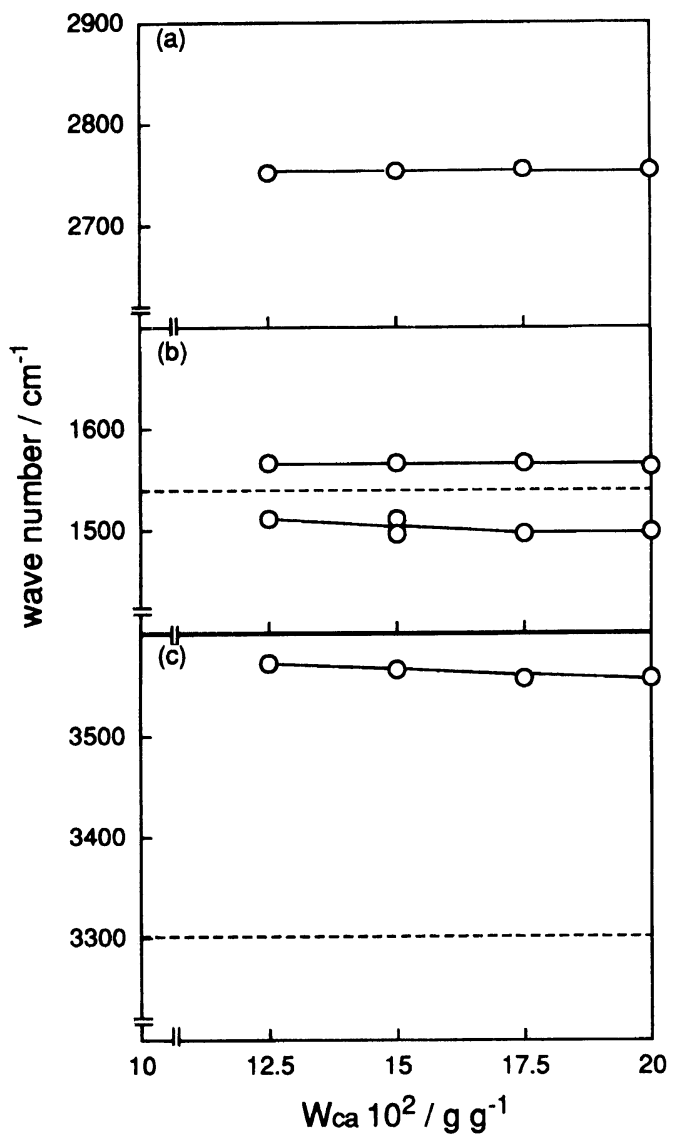

Figure 11. Calcium chloride concentration $W_{\text {ca }}$ dependence of IR resonance absorption wave number of (a) $\mathrm{NH}$ stretching of nylon 6,6 solution; (b) cationized $\mathrm{NH}\left(\mathrm{NH}_{2}{ }^{+}\right)$ stretching; (c) $\mathrm{NH}$ deformation (solid line). Broken line in the Figure denotes, NH stretching (b) and $\mathrm{NH}$ deformation (c) of nylon 6,6 solid film.

amide amine is only possible when $\mathrm{Cl}^{-}$in the coordination form of solvent (associated form) or $\mathrm{CH}_{3}-\mathrm{O}-\mathrm{H} \cdots \mathrm{Cl}^{-}$part in the associated form of solvent directly interacts with $\mathrm{NH}$ site. Furthermore, NH stretching at $3300 \mathrm{~cm}^{-1}$ (broken line in Figure $11 \mathrm{c})^{28-30}$ is shifted to higher frequency side (above $3550 \mathrm{~cm}^{-1}$ ) when contacted with solvent mixture with $W_{\text {ca }} \geqq$ 0.125 . This means that hydrogen bond between amide groups of polymer in solid is completely destructed by solvent mixture, again suggesting strong affinity of $\mathrm{Cl}^{-}$or the $\mathrm{CH}_{3}-\mathrm{O}-\mathrm{H}_{\cdots} \mathrm{Cl}^{-}$ to amide $\mathrm{NH}$ site of polymer in the solvent 
mixture. Introduction of such bulky complex to NH site may hinder the approaching of the other components to $\alpha-\mathrm{NH}$ methylene site at any $W_{\text {ca }}$.

\section{CONCLUSIONS}

The following conclusions were drawn from the studies on mixture of calcium chloride and methanol and nylon 6,6 solution.

1. The second virial coefficient obtained by light scattering method remarkably decreases with a decrease of $W_{\text {ca }}$ below 0.15 and was expected to be zero at $W_{\mathrm{ca}}=c a .0 .115$ (i.e., Flory's $\Theta$ solvent).

2. From value of conformation parameter and characteristic ratio, evaluated using a value of radius of gyration at the $\Theta$ state, the nylon 6,6 molecule is judged to be very flexible.

3. The viscosity of the nylon 6,6 in the mixture of calcium chloride and methanol reveals extraordinary $W_{\text {ca }}$ dependence near $W_{\text {ca }}=0.15$.

4. In the solvent mixture with $W_{\text {ca }}$ above ca. $0.05, \mathrm{CaCl}_{2}$ molecules associate forming metal halide complex with methanol molecules. The structure of the complex changes depending on $W_{\text {ca }}$, approaching to stable form, $\left[\mathrm{Ca}\left(\mathrm{CH}_{3} \mathrm{OH}\right)_{4}\right]^{2+}\left(\mathrm{Cl}^{-}\right)_{2}$, with an increase of $W_{\text {ca }}$ above 0.175 .

5. Dissolution of nylon 6,6 in calcium chloride-methanol mixture with $W_{\text {ca }} \geqq 0.1$ is realized at least by interaction of methanol and chlorine parts in the associated form of solvent mixture with amide carbonyl and amine: In the range of $W_{\text {ca }}<0.15$, selective absorption of extra solvated methanol molecules or weakly bound methanol molecules with the stable associate form of the complex to nylon 6,6 plays an important role to determine the very compact chain conformation of the nylon 6,6 chain. Dissolution of nylon 6,6 at $W_{\text {ca }}=0.15$ 0.25 (upper limit of dissolution) takes place by direct interaction of the very bulky and metastable associate form of solvent to polymer, which brings about large expansion of the nylon 6,6 chain in the solution.

\section{REFERENCES}

1. P. R. Saunders, J. Polym. Sci., 43, 131 (1961).

2. P. R. Saunders, J. Polym. Sci., A, 2, 3765 (1964).

3. E. G. Elias and R. Schumacher, Makromol. Chem., 76, 23 (1964).

4. K. Kamide, A. Kataoka, and T. Kawai, Makromol. Chem., 139, 221 (1970).

5. P. R. Saunders, J. Polym. Sci., 43, 273 (1961).

6. P. R. Saunders, J. Polym. Sci., 57, 131 (1962).

7. P. R. Saunders, J. Polym. Sci., A, 2, 3755 (1964).

8. B. S. Holmes, G. C. Chingas, W. B. Moniz, and R. C. Ferguson, Macromolecules, 14, 1783 (1981).

9. B. S. Holmes, W. B. Moniz, and R. C. Ferguson, Macromolecules, 15, 129 (1982).

10. R. A. Ford and H. S. B. Marshall, J. Polym. Sci., 22, 101 (1956).

11. A. Nakajima and K. Tanaami, Polym. J., 5, 248 (1973).

12. A. Passynsky, Acta Physicochem., U.S.S.R., 22, 137 (1947),

13. A. Passynsky, J. Polym. Sci., 29, 61 (1958).

14. C. Strazielle, "Light Scattering from Polymer Solutions, Light Scattering in Mixed Solvents," $M$. Huglin, Ed., Academic Press, New York, N.Y., 1972, Chapter 15, p 633, 650.

15. M. Hattori, T. Ohara, M. Miyazaki, and K. Kamide, unpublished results.

16. K. Kamide and M. Saito, Adv. Polym. Sci., 83, 1 (1987).

17. M. Kurata and Y. Tsunashima, "Polymer Handbook," 3rd ed, J. Brandrup and E. H. Immergut, Ed., A Wiley-Interscience Publication, New York, N.Y., 1989, Chapter VII/1.

18. Y. Marcus, "Introduction to Liquid State Chemistry", John Wiley \& Sons Ltd., New York, N.Y., 1977, Chapter 6. M. Tanaka, N. Matsuura, T. Tominaga, M. Yamamoto, and Y. Yamamoto, "Kagaku Sousetsu, No. 11, Ion to Youbai", The Chemical Society of Japan, Tokyo, 1976, p 175, Chapter 9.

19. G. Jones and H. J. Fornwalt, J. Am. Chem. Soc., 57, 2041 (1935).

20. D. Feakins and K. G. Lawrence, J. Chem. Soc., A, 212 (1966).

21. C. W. Davies and V. E. Malpass, Trans. Faraday Soc., 60, 2075 (1964).

22. L. B. Clapp, "Chemistry of the OH Group," Foundations of Modern Chemistry Series, PrenticeHall Inc., Englewood Cliffs, New Jersey, N.J., 1967, Chapter 2.

23. N. Ozeki, "Youbai Handbook", S. Yuasa, J. Tokura, S. Ohgawara, J. Kumanokei, and M. Senou, Ed., Kohdansya Scientific, Tokyo, 1976, p 329, Chapter 
II-3.

24. R. D. Shannon and C. T. Prewitt, Acta Crystallogr., B25, 925 (1969).

25. R. D. Shannon, Acta Crystallogr., A32, 751 (1976).

26. J. R. Schaefgen and C. F. Trivisonno, J. Am. Chem. Soc., 74, 2715 (1952).
27. R. E. Richards and H. W. Thompson, J. Chem. Soc., 1248 (1947).

28. S. Mizushima, T. Shimanouchi, and T. Tsuboi, $J$. Am. Chem. Soc., 73, 1330 (1951).

29. M. Tsuboi, Bull. Chem. Soc. Jpn., 22, 215 (1949).

30. M. Tsuboi, Bull. Chem. Soc. Jpn., 22, 255 (1949). 